1 Ministerio de Salud Pública (MSP) - Eldorado, Argentina.

2 Ministerio de Agricultura de la Nación (MAN) -

Eldorado, Argentina.

3 Ministerio de Educación (ME) - Neuquén,

Argentina.

\section{El Buen Vivir, camino del Movimiento Mundial de Salud de los Pueblos Latinoamérica hacia otra alternativa al desarrollo}

Good Living (Buen Vivir), the path of the Latin America People's Health Movement towards an alternative to development

Marcela Beatriz Bobatto', Gerardo Segovia2 ${ }^{2}$, Sandra Marín Rosas ${ }^{3}$

DOI: 10.1590/0103-11042020S102

Singular y Asombroso Singular y asombroso destino de un pueblo como los guaraníes (y otros pueblos) Marginados y periféricos nos obligan a pensar sin fronteras Tenidos como parcialidades desafían la totalidad Reducidos reclaman cada día espacio de libertad sin límites Pequeños exigen ser pensados a lo grande Son aquellos primitivos cuyo centro de gravedad Ya está en el futuro. Minorías que están presentes en la mayor parte del mundo. Bartolomé Meliá

Esas voces que vienen de los primeros tiempos hablan de los tiempos que vendrán Brotan de la memoria de los mayas, pero dicen lo que dicen para que la escuche el mundo,

Que a los tumbos busca rumbo, tanteando en la noche, perdido como ciego en tiroteo. Veinte capítulos, veinte granos de maíz. También nosotros, gentes de todos los colores somos granos de maíz.

$Y$ estas voces nos recuerdan que el centro del universo está en cada uno de nosotros, porque esta cada uno de los frutos que brotan a cada instante del tiempo y en cada lugarcito de la tierra. Y nos invitan a recrear el hilo roto de la vida, a sanar la violada dignidad de la naturaleza y a recuperar nuestra perdida plenitud. Eduardo Galeano 


\section{Introducción}

Desde la III Asamblea Mundial de salud de los pueblos en Ciudad del Cabo - Sudáfrica (2012), y luego en la I Asamblea Latinoamericana en Cuenca - Ecuador (2013), venimos como movimiento reflexionando con mucha fuerza, sobre la existencia de una crisis civilizatoria'.

Asistimos a una profunda crisis de la humanidad. Estamos presenciando las consecuencias de un capitalismo salvaje, antropocéntrico, patriarcal, neocolonial que lleva a destrucción acelerada de las condiciones que generan y soportan la vida, producto de haber abrazado la obsesión por dominar el universo ${ }^{\mathbf{2}, \mathbf{3}}$.

Estamos sufriendo las consecuencias de un modelo de desarrollo que ha profundizado cada vez más la brecha entre los países y dentro de cada uno de ellos, aumentado la pobreza, el desempleo, la desigualdad y la exclusión de amplios sectores de la población.

Un modelo que está dejando un progresivo deterioro del ambiente, agotamiento de los bienes naturales, pérdida de la biodiversidad agrícola y silvestre, desequilibrios ecológicos locales y globales y la propia desaparición de espacios de vida de las comunidades locales, generando problemas para el bienestar de la población, manifestándose con nuevas enfermedades y riesgos para la salud humana, como consecuencia del uso indiscriminado de agrotóxicos, de la creciente contaminación del aire, del agua y del envenenamiento de la tierra.

Un modelo hegemónico desde donde se normaliza el dominio y el exterminio contra los pueblos indígenas y campesinos, que margina particularmente a las mujeres y no respeta la libertad, los derechos humanos, y menos aún los derechos de la Madre Tierra, impulsando el despojo de los pueblos mediante la lógica del hiperconsumo irracional, el extractivismo y la mercantilización de la salud, impuestos violentamente, criminalizando la resistencia y la protesta social.

Este modelo está poniendo en riesgo la propia supervivencia de la humanidad ${ }^{\mathbf{4} 5}$. Este concepto dominante ha establecido que desarrollo equivale al desarrollo racional, y a la acumulación o crecimiento material y ha sido fuertemente incidido por el paradigma científico que nos acompaña hace siglos, conocido como paradigma newtoniano/ cartesiano, caracterizado por su visión mecanicista y fragmentaria de la vida, carente de análisis sistémico.

Pero la visión sistémica no es un descubrimiento reciente de la humanidad. La visión sistémica ha estado y está presente en la cosmovisión de los pueblos originarios de todo el planeta. Una de las cosmovisiones ancestrales que con mayor fuerza ha surgido en el mundo, es la de los pueblos originarios de América del sur, conocida como Buen Vivir.

El objetivo de este trabajo es dar a conocer la visión que tiene el MSP-LA sobre el Buen Vivir, nutrido de las cosmovisiones de los pueblos originarios del continente, desde una visión sistémica, como una propuesta alternativa al modelo de desarrollo capitalista. El artículo se estructura de la siguiente manera: en un primer título se exponen las cosmovisiones de los pueblos del AbyaYala (nombre con que se conoce al continente que hoy se nombra América), en un segundo título se comparten los sentipensares sobre el Buen Vivir, en un tercer título las características que se visualizan para este modelo de sociedad y posteriormente se desarrollan algunos de los escenarios donde se da visibilidad al Buen Vivir: agricultura, salud, economía y educación. Por último, se plantean los desafíos.

\section{Cosmovisiones de los pueblos del AbyaYala}

En cada una de las culturas se produce una cosmogonía producto de la relación de las personas con la naturaleza. Es la forma en que los seres humanos representan el origen del mundo, su lugar en el cosmos, su concepción del universo, el sentido del transcurrir humano que va creando una imagen del mundo que una sociedad se da a sí misma resultante de 
los saberes más variados, del 'cosmocimiento', tradiciones e intuiciones. El 'cosmocimiento' es una palabra propuesta en la 3ra. Cumbre Continental de los Pueblos Originarios de Abya Yala ${ }^{6} \mathrm{y}$ hace referencia a que no es solamente el conocimiento del ser humano, que en la cultura antropocéntrica se asocia a poder y prestigio social, sino al conocimiento de todos los seres visibles e invisibles, orgánicos y no orgánicos, tangibles e intangibles ${ }^{7}$.

Las sabidurías ancestrales, desde la profundidad de las cosmovisiones de los pueblos que desde siempre habitaron nuestra AbyaYala, nos recuerdan que hay otras maneras de sentir y vivir la vida, que pertenecemos a una fuerza superior a nosotras/os, que al mismo tiempo nos constituye.

Desde ellas surge esta concepción de Buen Vivir, que para el Movimiento Mundial por la Salud de los Pueblos tiene la fuerza de la práctica y de la vivencia cotidiana de los pueblos indígenas, de campesinos y de otros colectivos que vienen trabajando en la construcción del paradigma biocéntrico.

A esta otra manera de concebir la vida y de vivirla, quichuas, quechuas y aymaras, en Ecuador y Bolivia, lo nombran como Buen Vivir, sumakkawsay, suma qamaña. Desde algunos idiomas mayas, el Buen Vivir se traduce en expresiones como ütz.' k.'aslemal, raxnaqil, ralch.'och'7,8.

Desde el pueblo mbyaguaraní es eltekóporá en elyvymara' ey, la prodigiosa tierra sin mal, desde el pueblo wichi, la buena voluntad wichi, desde el pueblo nahuat, tinemisujsulyek, desde el pueblo-nación mapuche kümemongen, t'banilchunclal, buena vida para el pueblo maya mam ${ }^{9,10}$.

Como integrantes del MSP-LA tenemos el convencimiento de que el Buen Vivir, el Vivir Bien es el camino para salir de este sistema depredador. Es la única alternativa al modelo capitalista colonial, a la modernidad, al desarrollo y al extractivismo.

El buen vivir milenario puede salvar el planeta, las cosmovisiones emancipadoras de los pueblos originarios se revitalizan, se reconstituyen y pueden ser la base de los proyectos políticos de los pueblos luego de 521 años de resistencia. Vamos hacia la libre autodeterminación y autonomía de los pueblos y en este camino desde nuestro Movimiento buscamos aportar para construir la Soberanía de la Salud de nuestros pueblos².

En los últimos años el Buen Vivir se ha presentado como una importante corriente de reflexión en América Latina"1. Implica un cambio profundo en el modelo civilizatorio actual.

\section{Sentipensares sobre el Buen Vivir}

¿Qué es el Buen Vivir, el vivir bien, el sumakkawsay, la tierra sin males?

En esta parte del artículo, recuperamos el término sentipensar a partir de una concepción holística, entendido como el proceso mediante el cual se trabaja conjuntamente el pensamiento y el sentimiento ${ }^{\mathbf{1 2}}$. Es el sentipensamiento reconstituido de los pueblos del AbyaYalay de diversas construcciones de los movimientos sociales en su camino de resistencia y esperanza ${ }^{7}$.

Del idioma kichwi o runa shimi: Sumak: plenitud, completo, realizado, belleza, excelencia. Kawsay: vida, existencia, convivencia. Vida o existencia plena o plenitud de vida.

Ali o Allí: bueno. Allí kawsay: bien vivir o buen vivir, se entiende una vida social, material y ética en el ámbito humano ${ }^{13}$.

Sumakkawsay trasciende el allí kawsay o buen vivir por su carácter ético, estético, cosmológico, holístico. Es una forma de existencia plena, equilibrada, modesta, armónica, que se alcanza colectivamente en base al cultivo de las relaciones de reciprocidad con todos los seres vivos ${ }^{13}$.

El Buen Vivir, es un proyecto político de vida; es el proceso de satisfacción y bienestar colectivo para potenciar la vida en equilibrio de la madre naturaleza y el cosmos para lograr la armonía ${ }^{7}$.

El Buen Vivir es otra manera de concebir la vida y de vivir la. Es una manera diferente 
de experimentar la existencia. Esta manera de pararse frente a la vida es profundamente ecológica, espiritual, política y económica.

Es la idea de vivir en plenitud; de vivir mejor con lo necesario; de disfrutar de una vida más simple, del placer de la convivencia con todo lo que posibilita la vida; de buscar la autonomía y heteronomía como práctica de libertad, es concretar el sueño de hacer juntas y juntos el vivir en relación con el todo.

Es integrar el pensar, el sentir y el accionar en el vivir. El Buen Vivir propone la vida en armonía de todos los seres y elementos de la naturaleza. Parte de la concepción que todas las personas somos naturaleza y que somos interdependientes unas con otras, que existimos a partir del otro/a, que todo está interconectado, interrelacionado y es complementario.

El respeto por todo lo que hace posible la vida, es entonces saber vivir y saber convivir.

El Buen Vivir promueve la cosmoconvivencia y la complementariedad, la libertad y derechos de la naturaleza, la libre determinación de las personas y los pueblos, de las identidades, de los cuerpos, sexualidades y territorios; es colectivo y propicia el cuidado de la vida y el placer, los amores, la alegría y las distintas maneras de expresarlo, así como el cosmocimiento sentipensante ${ }^{7}$.

Buscar esa armonía no implica desconocer los conflictos sociales y las diferencias sociales y económicas, ni tampoco negar que estamos en un orden hegemónico, el capitalista, y bajo un modelo antropocéntrico. Implica reconocer que dentro del capitalismo no hay lugar para la vida, no hay lugar para los sueños, solo queda la certeza de la acumulación en pocas manos, de la muerte y el exterminio de todas las manifestaciones de vida.

Desde este paradigma biocéntrico construimos colectivamente una nueva forma de vida y generamos otros mundos posibles. Se nos abre la posibilidad de crear, de pensar con esperanza, de sentir y experimentar que podemos dar repuestas ante la crisis de la existencia.

El Buen Vivir, el vivir bien es mucho más que un modelo intelectual,y que una propuesta académica-política. Su fuerza radica en que es una práctica de vida que implica la posibilidad de aprender de realidades, experiencias, prácticas y valores presentes en muchos lugares, escurriéndose triunfal a través de las grietas de esta civilización capitalista"1.

Desestabiliza y subvierte el orden patriarcal, colonial y capitalista en que nos hemos socializado. Es un cuestionamiento radical a las formas de dominación, sometimiento, control, despojo y violencia.

La práctica de esta concepción conlleva el desafío permanente del ejercicio - en la vida cotidiana de las personas, instituciones y organizaciones- de la descolonización y despatriarcalización, democratizando todos los espacios posibles donde transcurre la vida, así como la liberación de las distintas opresiones, de manera que se logre la justicia a favor de los pueblos, las mujeres y la madre tierra ${ }^{11}$.

Para una mayor comprensión sintetizamos y compartimos en el cuadro 1 algunas de las características inherentes a esta propuesta ${ }^{7,14}$.

Cuadro 1. Características del Buen Vivir

Integralidad

Colectividad
Compleja red entre todos los seres, sus relaciones, interconexiones e interdependencias. Se concibe la existencia como un todo en equilibrio. A esta relación estrecha entre todos los seres, fenómenos, ámbitos, aspectos se la denomina cosmoconvivencia.

Se reconoce la vida en todo lo que existe en el cosmos. Todos los seres tienen, entre sí la responsabilidad del cuidado de la vida. Busca la vivencia en comunidad. Significa asumir la individualidad, la libertad, el compromiso por la plenitud de todo lo que genera vida. Implica construcción de objetivos y metas comunes, considerando los intereses y necesidades de quienes lo constituyen. 
Cuadro 1. (cont.)

Complementariedad

Libertad y derechos de la madre naturaleza

Autonomías de las personas y los pueblos

Aceptación por las diferencias

Equilibrio con la naturaleza

Defiende la identidad

Promoción del placer, la alegría y las distintas maneras de expresarlo

Construcción colectiva del conocimiento
En la vida todo es complementario, las partes diversas hacen posible entender la complementariedad, todos/as y todo tienen un complemento. La complementariedad evita la competencia, es la ayuda mutua y permanente en la comunidad. Los mundos humanos o sociales se complementan con el mundo natural o material y el mundo espiritual donde caben o existen las deidades o energías. Estos mundos a la vez son interdependientes entre sí. Somos seres completos, tenemos nuestra contraparte en nosotros/as mismos/as.

La madre naturaleza tiene y da vida de manera permanente de acuerdo con sus ciclos vitales y la vida humana está en equilibrio y armonía con ella. Desde esta concepción, la acción humana no daña, no provoca la destrucción del cosmos, la tierra y los seres que cohabitamos. Entendemos a la naturaleza como sujeto de derechos y no simplemente como objeto de propiedad.

Implica la posibilidad y capacidad de ejercer la libre determinación sobre los cuerpos, vidas y territorios que posibiliten la plenitud de la Vida. Es la forma de organización independiente que garantiza la existencia, la satisfacción de las necesidades comunes, en la búsqueda del equilibrio, a través del cuidado y reproducción de la vida.Busca caminos para procurar la plenitud y la realización individual en la construcción de comunidades sanas y armónicas. Promueve la autodeterminación, la cosmoconvivencia, el cosmocimiento, la reciprocidad y el cuidado.

Postula el respeto. Cada cultura o región tiene una forma diferente de sentipensar y hacer según su cosmovisión. Para vivir bien y en armonía es necesario respetar esas diferencias. Busca soluciones a partir de lo diverso, no de lo único.

Cuida la red de la vida a partir de los acuerdos con la madre naturaleza, el equilibrio y la colectividad. Llevar una vida de equilibrio con todos los seres dentro de una comunidad. Lo más importante es la vida y la armonía. Vivir sencillamente, en una sociedad equitativa e inclusiva.

Valora y recupera la identidad personal y de los pueblos. La identidad implica disfrutar plenamente una vida basada en valores que han sido legados por las familias y comunidades que vivieron en armonía con la naturaleza y el cosmos.

Propicia espacios y tiempos para compartir el juego, el gozo del intercambio, la danza, la creatividad en todos los espacios de la vida. Le da una especial importancia a la celebración de cada momento de la vida de las personas y de las comunidades. Festivo, celebrativo, alegre, agradecido.

No se concibe como la tarea de un grupo de especialistas, sino que es parte de un compartir colectivo que va constituyendo a los sujetos en sí, como actores, creadores y diseñadores. Al construir conocimientos partimos de saberes previos, que nacieron de prácticas existentes en nuestros pueblos. En este caminar colectivo, el trabajo y la producción se enriquece desde las tantas miradas que completan, critican, problematizan una perspectiva individual.

\section{Escenarios donde se da visibilidad al Buen Vivir}

El paradigma científico fragmentario mecanicista, ha llegado a su ocaso y ha quedado absolutamente obsoleto, debe dar lugar a un nuevo paradigma científico de visión sistémica que analiza y entiende a la vida, la naturaleza y el cosmos como una totalidad integrada, en que todo está interconectado. Esta es una visión con profundas implicaciones no sólo para la ciencia y la filosofía, sino también para la educación, la ecología, la economía, la sanidad y la vida cotidiana. En este apartado presentamos algunos de los escenarios donde podemos visibilizar esta propuesta: agricultura, salud, educación y economía para la vida (figura 1). 
Figura 1. Escenarios del Buen Vivir

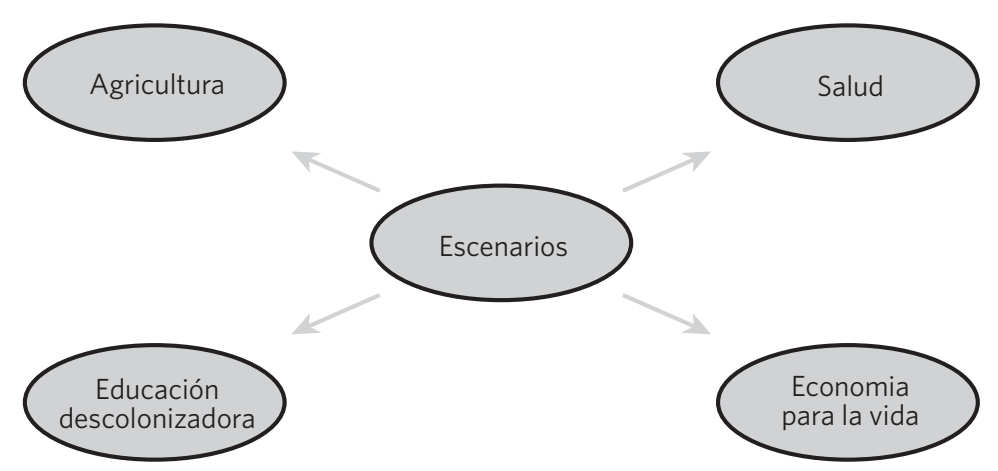

Fuente: Marin Rosas S, Bobatto M¹

\section{Agricultura}

Mantener durante miles de años la biodiversidad agrícola ha sido uno de los factores que permitió a los/as agricultores/as de todo el mundo asegurar su independencia productiva y la soberanía alimentaria de sus comunidades ${ }^{15}$.

La sociedad industrial, capitalista, se apropió del germoplasma a través del uso de patentes, registros de variedades y otras violaciones 'legales' a los derechos de los pueblos. Desde la revolución verde se impuso la producción agrícola industrial como único camino para salvar del hambre al mundo. Esto llevó a que los/as agricultores/as reemplacen sus semillas tradicionales por las variedades mejoradas (híbridos, organismos genéticamente modificados, clones, etc.) altamente dependientes de insumos industriales (herbicidas, insecticidas, fertilizantes sintéticos, maquinarias pesadas).

En este contexto surge como reacción a este modelo productivo hegemónico el concepto de la agroecología, con especial fuerza en Latinoamérica, como un nuevo enfoque y paradigma de las ciencias agrarias que pretende aportar estrategias y criterios para el diseño, manejo y evaluación de agroecosistemas sustentables.
La propuesta del Buen Vivir propicia la producción basada en conceptos de agroecología, ya que ésta conserva los bienes naturales elementales de la producción de alimentos tales como el suelo, agua y biodiversidad. Estas acciones se basan en el respeto a las comunidades rurales (quienes aportan el material genético mejor adaptado a las condiciones locales) y a los principios éticos y humanos en la realización de estas actividades. Reincorpora la agricultura a las comunidades, valora y dignifica el trabajo campesino y recupera las formas de vivencia en comunidad. Propone la no dependencia de insumos externos, eliminando la utilización de agrotóxicos, protege y guarda las semillas nativas y criollas para que en un futuro se evite el uso de productos transgénicos.

La agroecología es una nueva ciencia en construcción, un paradigma de cuyos principios y bases epistemológicas nace la convicción de que es posible reorientar el curso alterado de procesos de uso y de manejo de recursos naturales, de forma a ampliar la inclusión social, reducir los daños ambientales y fortalecer la soberanía alimentaria. Surge como un nuevo enfoque, más amplio, que reemplaza la concepción puramente técnica por una que incorpora la relación entre la agricultura y el ambiente 
global y las dimensiones sociales, económicas, políticas y culturales. Y posee, sobre todo, un gran componente ético (cuadro 2) ${ }^{\mathbf{1 6}}$.

Cuadro 2. Enfoques productivista y agroecológico

\begin{tabular}{l} 
Enfoque productivista \\
\hline Agricultura Intensiva \\
-Visión reduccionista \\
- Hay un solo tipo de agricultura \\
-La ética: un valor difuso \\
-Falta de una óptica sistémica \\
- Importancia de los componentes \\
-Reconoce sólo el conocimiento científico \\
- Lo local es poco importante \\
-Énfasis en el rendimiento de pocos cultivos rentables \\
- Uso exclusivo del territorio \\
- No incorpora el costo ambiental \\
- Minimiza aspectos socioculturales \\
-Principalmente basada en tecnologías de insumos \\
- Lo científico genera la tecnología \\
- Considera a la biodiversidad principalmente como fuente \\
de genes
\end{tabular}

Fuente: Elaborado a partir de Sarandon \& Flores, 201416

Hoy más que nunca es necesario recuperar y mantener la enorme riqueza de la biodiversidad agrícola y alimentaria, reconociendo los derechos de los campesinos, indígenas y agricultores a la tierra, al territorio, al agua y a los recursos naturales, para construir un nuevo modelo de agricultura y desarrollo rural.

\section{Salud}

El derecho a la salud es un derecho humano fundamental, es el derecho a vivir en plenitud. Desde el Buen Vivir, desde este paradigma biocéntrico, construimos nuevos conceptos de salud que tiene que ver con la 'salud de los ecosistemas', la 'salud en manos de la comunidad', la 'salud integral'. La salud como un proceso vital, integrador de nuestro ser con el Todo ${ }^{17}$.

Desde ese punto de vista, la enfermedad, no es lo contrario a la salud, sino que

\section{Enfoque agroecológico}

Agricultura Sustentable

-Enfoque holístico

-Existen varios modos de hacer agricultura

-La ética: un valor fundamental

-Empleo de una óptica sistémica

- Importancia a las interrelaciones entre los componentes

de los agro- ecosistemas

-Reconoce el conocimiento científico y otros. Concepto

pluriepistemológico

-Lo local es importante

-Énfasis en el agro ecosistema y ecosistemas relacionados

-Uso múltiple del territorio

- Incorporación del costo ambiental

- Revaloriza aspectos socioculturales

- Principalmente basada en tecnologías de procesos

-Participación del agricultor en la generación de tecnología

-Reconoce la importancia de la biodiversidad como forma de cultivo y soporte de vida, además de fuente de genes. hace parte del devenir vital y se la considera como un proceso autoorganizativo en un ser humano dado. La salud como la enfermedad son parte de un proceso teleológico, vital, cibernético, autoecoorganizativo y por lo tanto autoecocontrolado ${ }^{\mathbf{1 8}, 19}$.

Desde esta nueva propuesta es necesario pensar y transitar nuevas maneras de resignificar la salud y la salud pública, comprendiendo a esta última como salud del pueblo.

Además, es necesario establecer un diálogo desde la transdisciplinariedad, donde estén presentes los distintos saberes y prácticas, donde se promueva la incorporación de las diferentes prácticas ancestrales de salud de cada uno de los pueblos. Es necesario fomentar otras prácticas saludables que tengan que ver con la medicina natural, la utilización de las plantas, semillas, flores, alimentación saludable, masajes, diferentes rituales, respetando cada manera de sanar de los pueblos ${ }^{20,21}$. 
Es necesario advertir que hay prácticas milenarias utilizadas por el sistema intercultural neoliberal, marco desde donde se piratea el conocimiento ancestral milenario para mercantilizarlo. Debe haber un alto a esta barbarie y poner en su lugar a las prácticas milenarias para el Buen Vivir de los pueblos.
Integrar estas prácticas milenarias con las provenientes de otras medicinas de modo que se complementen en beneficio de las personas y sus ambientes. Características contrastantes de la Salud desde el antropocentrismo y en el paradigma biocéntrico son presentadas en el cuadro 3.

Cuadro 3. La Salud desde el antropocentrismo y en el paradigma biocéntrico

\begin{tabular}{ll}
\hline La Salud desde el Antropocentrismo & La Salud en el Paradigma biocéntrico \\
\hline Problema Médico & Asunto Vital \\
Modelo de normalidad & Proceso de aprendizaje permanente \\
Expropiación del cuerpo & Conciencia de lo que somos, sabemos y podemos desde lo sistémico \\
Cosa o mercancía (cuantificable) & Salud como derecho \\
Manipulación, dominación y control & Auto-eco organización, emergencia, incertidumbre \\
Dependencia & Libertad \\
Análisis y especialización & Transdisciplinariedad \\
Homogeneización & Singularidad \\
Enfermedad como daño & Enfermedad como lenguaje vital \\
Biológico, Estático e Individual & Integral, Dinámico y Universal \\
\hline
\end{tabular}

Fuente: Payan S|22

\section{Educación y formación descolonizadora}

Cuando vemos la alarmante situación del planeta tierra, la crisis que atravesamos como humanidad y comprendemos la relación existente entre la educación, la manera en que percibimos el mundo y la manera en que actuamos, no podemos dejar de interrogarnos y replantearnos la educación vigente.

En el análisis del paradigma educativo dominante constatamos que ha sido fuertemente modelado por el paradigma científico newtoniano/cartesiano, caracterizado por su visión mecanicista, positivista, reduccionista y fragmentaria de la vida. Esta visión que ha constituido la base de la educación moderna, no solamente ha fragmentado el conocimiento, sino también al ser humano de sí mismo, al ser humano de la naturaleza colocando a este afuera y arriba como dominador.

Con diversos descubrimientos, con la evolución de algunas ramas de las ciencias como en la física y en la biología, el paradigma científico fragmentario mecanicista, ha llegado a su ocaso dando lugar a un nuevo paradigma científico de visión sistémica que analiza y entiende a la vida, la naturaleza y el cosmos como una totalidad integrada, en la que todo está interconectado.

Pero la visión sistémica no es un descubrimiento reciente de la humanidad ${ }^{\mathbf{2 3}, \mathbf{2 4}}$. Ella ha estado y está presente en la cosmovisión de los pueblos ancestrales de todo el planeta ${ }^{25}$ Es por ello que tanto movimientos sociales como académicos reclaman la recuperación de estos saberes.

Desde la propuesta del Buen Vivir es necesario profundizar en un sistema educativo comunitario teniendo en cuenta que todas y todos enseñamos y todas y todos aprendemos. Nosotros y nosotras sabemos algo, a la vez ignoramos algo. Por eso aprendemos siempre ${ }^{26}$. Desde esta concepción, la educación se inicia 
en el espacio doméstico, en familia y en comunidad. Continúa en escuelas que sintonizadas con el espíritu y la filosofía de cada pueblo puedan acrecentar y valorar saberes populares y aportar desde el campo científico académico.

A la educación podemos considerarla como uno de los instrumentos más poderosos para realizar la transformación de la realidad, por ello uno de los desafíos más difíciles será el de modificar nuestro pensamiento de manera que enfrente la complejidad creciente, la rapidez de los cambios y lo imprevisible que caracterizan nuestro mundo. Debemos reconsiderar la organización del conocimiento, derribar las barreras tradicionales entre las disciplinas y concebir la manera de volver a unir lo que hasta ahora ha estado separado.

Debemos asumir al Buen Vivir, el Vivir Bien como una categoría en permanente construcción, reproducción y retroalimentación. El reto es cómo aprovechar todos los conocimientos disponibles. No podemos cerrarnos a los avances de la ciencia, especialmente la cuántica y la relativista, desde este paradigma, surgen conceptos como complejidad y pensamiento sistémico. La ciencia va al encuentro de la sabiduría de los pueblos ancestrales y logra ver parte de lo que ya se sabía, para descubrir que no hay que dividir la vida para entenderla porque si la fraccionamos deja de ser vida ${ }^{\mathbf{2 3}, 24,27}$.

\section{Economía para la vida}

El modelo capitalista tiene en su esencia una economía basada en la maximización de las ganancias, en la lógica del lucro y la acumulación. Ser más implica tener más. En cambio en el Buen Vivir tiene a la reciprocidad como valor básico de la economía. Es una economía distinta, una economía social y solidaria, diferente a la caracterizada por una supuesta libre competencia, que alimenta la especulación financiera. Es una economía que tiene que reencontrarse con la naturaleza, para mantenerla y no para destruirla; en definitiva, para retornar a su valor de uso y no al valor de cambio ${ }^{28}$.
Se necesita un proceso paulatino de desmercantilización de las actividades humanas, fundado en tres pilares básicos: reciprocidad, redistribución, y redimensionamiento del mercado ${ }^{29}$.

La reciprocidad plantea varios elementos de interés para avanzar en la desmercantilización en la medida en que se trata de un tipo de relación social que puede contribuir a la cohesión social y al aumento de la confianza mutua, favoreciendo de esa forma una mayor equidad, así como el desarrollo de capacidades colectivas. También favorece la democracia y la participación, incrementando la capacidad de decisión de las personas y su empoderamiento. Del mismo modo puede dar cabida a múltiples tareas asociadas a los cuidados y a la esfera reproductiva, favoreciendo la equidad de género siempre, eso sí, que no implique que tareas que hoy en día se han mercantilizado vuelvan a ser responsabilidad única de las mujeres ${ }^{29}$.

La redistribución constituye la segunda de las propuestas que pueden vertebrar una estrategia de desmercantilización para el Buen Vivir. Frente a las relaciones basadas únicamente en el mercado y en la necesidad de que las personas deban afrontar individualmente sus problemas independientemente de su condición, la redistribución favorece una mayor equidad y cohesión social, contribuyendo también a la confianza mutua y al incremento del bienestar colectivo En esa misma línea, la apuesta por elementos de redistribución frente a la lógica del mercado contribuye a la idea del bien común frente a la del interés individual, al tiempo que obliga a profundizar y consensuar democráticamente los objetivos cambiantes sobre los que basar la redistribución. Además, la redistribución como elemento de relación social puede contribuir a la eficiencia social y ecológica, mediante la provisión de servicios públicos sostenibles no necesariamente rentables en términos estrictamente de negocio.

Es preciso considerar también las posibilidades existentes en el propio ámbito del intercambio de mercado. Se trata de propuestas que irían en la línea de un redimensionamiento del mercado y de una reconsideración del 
papel que el mismo juega y debe jugar en la sociedad, con el objetivo de transitar desde una sociedad de mercado hacia una sociedad con mercados ${ }^{29}$.

Debe plantearse la necesidad de limitar la escala de los mercados, favoreciendo el funcionamiento de mercados locales, en pro de una mayor cohesión interna desde la perspectiva de la rentabilidad social y del medio plazo. Además, es preciso generar una institucionalidad a diferentes escalas capaz de limitar los abusos que casi necesariamente se generan en el funcionamiento del mercado, estableciendo una clara regulación del mismo para hacer que funcione al servicio de la sociedad.

Es evidente que se trata de retos complejos que requieren iniciativas y esfuerzos capaces de superar las dificultades existentes en las sociedades actuales. Sin embargo, existen hoy en día experiencias diversas para estudiar y analizar, las cuales pueden representar el germen de alternativas para una descentralización y democratización de los mercados que podrían favorecer una paulatina desmercantilización de la sociedad, y que surgen como respuesta a la crisis generada por el paradigma económico reinante. En este ámbito se sitúan distintas prácticas sociales que, aun dentro de la esfera del mercado, apuestan por un redimensionamiento y una reorientación hacia una economía socialmente justa y sostenible. Entre ellas pueden citarse las iniciativas que son ejemplo de estas nuevas economías: la economía colaborativa $^{30}$, la economía a escasa humana ${ }^{31,32}$, la economía del bien común ${ }^{33}$, la economía civil $^{34}$, y como ejemplo de actividades que generan una nueva economía: la producción entre pares, el cooperativismo comunitario, movimiento de consumo responsable, el de bienes comunes, instituciones microfinancieras, la banca ética, las ferias francas, mercados alternativos, etc.

El Buen Vivir pretende construir comunidades y sociedades en las que lo individual y lo colectivo vivan en complementariedad entre sí y en armonía con la naturaleza, y en las que la racionalidad económica se reconcilie con la ética y el sentido común. Constituye un paso cualitativo importante al pasar del desarrollo sustentable y sus múltiples sinónimos, a una visión diferente, más rica en contenidos y más compleja. No es una alternativa de desarrollo: es una alternativa al desarrollo?

\section{Desafíos}

El gran desafío que tenemos es, sin duda, encontrar una manera de desarrollarnos que no genere desequilibrios naturales y sociales y que a su vez respete nuestra salud y la de la madre tierra, desafío que nos urge resolver considerando que cada vez somos más cantidad de seres humanos en el planeta y que los niveles de contaminación, enfermedades, diferencias sociales y destrucción aumentan exponencialmente.

Otro de los desafíos es seguir profundizando este proceso donde la tarea es descolonizadora y despatriarcalizadora. Poner énfasis en la descolonización intelectual para poco a poco descolonizar la economía, la política, la educación, la sociedad 7 .

Además, es necesario hacer realidad los derechos de la naturaleza; que significan alentar políticamente su paso de objeto a sujeto, como parte de un proceso centenario de ampliación de los sujetos del derecho. Lo central de los derechos de la naturaleza es rescatar el derecho a la existencia de los propios seres humanos.

Los derechos de la naturaleza necesitan, y a la vez originan, otro tipo de definición de ciudadanía, que es necesario construir en lo social pero también en lo ambiental. El concepto original de ciudadanía propone al individuo independiente y aislado de su contexto social. Las libertades individuales con que nos seduce el sistema patriarcal-capitalista-mercantil niegan el entramado social humano, la necesidad que tenemos unos de otros, nuestro ser colectivo, el nosotros en lugar del yo. Proponemos profundizar en el concepto de cuidadanía, que defiende y cuida la vida colectivamente, creando vínculos sociales 
inspirados en la matrística, dejando de lado el de ciudadanía, por obsoleto e individualista. La matrística es una cultura donde el centro es la cooperación, la participación, el cuidado, la atención, la alegría ${ }^{35}$.

En ese sentido, la construcción del Buen Vivir, puede ser útil para encontrar incluso respuestas globales a los retos que tiene que enfrentar la humanidad.

El sumakkawsay o Buen Vivir o vivir bien en tanto cultura de la vida en plenitud, con diversos nombres y variedades, ha sido conocido y practicado en diferentes períodos en las diferentes regiones de la madre tierra. Este concepto no solo tiene un anclaje histórico en el mundo indígena; se puede sustentar también en otros principios filosóficos: ecológicos, feministas, cooperativistas, marxistas, humanistas. Por lo tanto, es necesario asumir el reto de construir esta utopía en otros lugares del planeta inclusive en los países industrializados.

Es importante fortalecer los espacios locales, y ayudar a que esos grupos que han manejado durante mucho tiempo una forma diferente de relación con el entorno puedan hacerse cada vez más fuertes. Pero al mismo tiempo hay que construir respuestas globales; por ejemplo, para desarmar las instituciones y prácticas que alientan la especulación financiera, debemos impedir que la humanidad incursione en una pesadilla tecnológica totalitaria. Para lograrlo requerimos otros niveles de organización plural de las sociedades mundiales, desde donde se podrá plantear con mayor claridad y profundidad soluciones globales. Y en ese campo el Buen Vivir o los buenos convivir es son también una propuesta para toda la humanidad. Humanidad descolonizada, reconstituida, descodificada de dominación que sienta un ser cosmogónico y no antropocéntrico.

\section{Colaboradores}

Bobatto MB (0000-0002-2853-1642)* contribuyó en la concepción, planificación, análisis e interpretación de datos, en la elaboración del borrador, revisión crítica del contenido y en la aprobación de la versión final del manuscrito. Contribuyó específicamente sobre la temática de salud y de economía. Segovia G (00000002-2864-2086)* contribuyó en la concepción, planificación, análisis e interpretación de datos, en la elaboración del borrador, revisión crítica del contenido y en la aprobación de la versión final del manuscrito. Contribuyó específicamente sobre la temática de Agroecología. Rosas SM (0000-0003-0086-950X)* contribuyó en la concepción, planificación, análisis e interpretación de datos, en la elaboración del borrador, revisión crítica del contenido y en la aprobación de la versión final del manuscrito. Contribuyó específicamente sobre la temática de Educación. 


\section{Referencias}

1. Marin Rosas S, Bobatto M. Aproximaciones al BuenVivir, Sumak Kawsay, Sumajqamaña, Ütz.' K.'aslemal, Lekilkujlejal, Kümemongen, Yvymará'ey -La tierrasin Males-, Vida en Plenitud, TinemisujsulYek, T'banilchunclal. [internet]. Cuenca: Equipo comunicándonos; MSP; 2017. [acceso en 2019 mayo 20]. Disponibleen: http://idepsalud.org/wp-content/uploads/2018/01/APROXIMACIONES-AL-BUEN-VIVIR. pdf.

2. Movimiento por la Salud de los Pueblos Latinoamérica. Declaración I AsambleaMovimiento Mundial de Salud de los Pueblos de Latinoamérica y el Caribe [internet]. Cuenca: Movimiento por la Salud de los Pueblos Latinoamérica; 2013. [acceso en 2019 mayo 20]. Disponible en: https://docs.wixstatic.com/ugd/ c9aldc_f35781b0516c423b8f675c53249897al.pdf.

3. Boff L. Ecología: grito de la Tierra, grito de los pobres. Buenos Aires: Editorial Lumen; 1996.

4. Capra F. El Punto Crucial. Buenos Aires: Editorial Troquel; 1999.

5. Quintero P, organizador. Crisis civilizatoria, Desarrollo y Buen Vivir. Buenos Aires: Del Signo; 2016. Colección El Desprendimiento.

6. $3^{\circ}$ Cumbre Continental de los Pueblos Originarios de Abya Yala; 26-30 mar. 2007; Iximche (Guatemala); 2007 (internet). [acceso en 2019 ene 21]. Disponibleen: http://www.cumbrecontinentalindigena.org/ iximche_conclusiones.php.

7. Cochoy Alva MF, YacNoj PC, Yaxón I, et al. 'ilajKaslemal - El Raxnaquil Kaslemal -El Buen Vivir de losPueblos de Guatemala- Guatemala: Edición PNUD; 2014.

8. Bretón V, Cortéz D, García F. En busca del Sumak Kawsay. Rev. Ïconos. Cs. Sociales. 2014; (48):9-24.

9. Mampaey M. Salud y cosmovisión reproductiva en la cultura Mbya Guarani. Buenos Aires: Tierra adentro ediciones; 2011.
10. Palmer J H. La Buena Voluntad Wichi - Una espiritualidad indígena. Buenos Aires: Editorial Grupo de trabajo Ruta 81; 2005.

11. Gudynas E. Debates sobre el desarrollo y sus alternativas en América Latina: una breve guía eterodoxa. En: Lang M, Mokrani D, editores. Más allá del desarrollo, grupo permanente de trabajo como alternativas al desarrollo, fundación Rosa Luxemburgo y AbyaYala. Quito: El Conejo; 2011b.

12. Torre S, Moraes MC. Fundamentos y estrategias para reencantar la educación. Archidona: Editorial Aljibe; 2005.

13. Maldonado RL. El SumakKawsay como alternativa al desarrollo Módulo didáctico $\mathrm{N}^{\circ} 4$. Ecuador: Escuela de gobierno y políticas públicas para las nacionalidades y pueblos del Ecuador;2010.

14. Choquehuanca D. 25 Postulados para entender elBuenVivir, VivirBien. Revista tierra y libertad [internet]. Tierra y Libertad. 2010 feb 3. [acceso en 2019 abr 10]. Disponible en: http://indigenaslibertarios. blogcindario.com/2010/02/00055-25-postulados-para-entender-el-vivir-bien-entrevista-con-david-choquehuanca-bolivia.html.

15. Segovia G. Sustentabilidad y agroecología. Posadas Argentina: UNAM Facultad de Humanidades y Cs. Sociales; 2007.

16. Sarandon S, Flores C. Agroecología: bases teóricas para el diseño y manejo de agrosistemas sustentables. Buenos Aires: UNP; 2014.

17. Monsalvo J. Salud de losecosistemas: unpensamiento articulador [internet]. Alta alegremia. 2013 ago 5. [acceso en 2019 ago 5]. Disponible en: http://www. altaalegremia.com.ar/contenidos/salud_ecosistemas_pensamiento_articulador.html.

18. Payan de la Roche JC. Lánzate al vacío, se extenderán tus alas. Diálogos sobre sociedad, salud y libertad. Bogotá: Mcgraw Hill; 2000. 
19. Payan de la Roche JC. Aproximaciones al concepto de la salud desde una mirada alternativa [internet]. Barcelona: Terapia Neural; 2002. Disponible en: http:// www.terapianeural.com/publicaciones/14-articulos-y-publicaciones/del-concepto/103-aproximaciones-al-concepto-de-salud-desde-una-mirada-alternativa.

20. Marin S, Marcus A. Principios fundamentales de laRed Jarilla de Plantas Saludables de la Patagonia. Buenos Aires: Ediciones de laBruja; 2011.

21. Sarandón S, Bobatto M, Segovia G. Experiencias de la agroecología en Misiones. Breve historia de la agroecología en la argentina: orígenes, evolución y perspectivas futuras. Agroecología. 2015; 10(2):93-102.

22. Payan SI. Dimensiones y escenarios de los paradigmas. Cuad. Emancipación [internet]. 2009 [acceso en 2019 mar 3]; (4):1-15. Disponible en: http://www. altaalegremia.com.ar/contenidos/Cuadernillo_N_1_-_ Paradigmas.html.

23. Morin E. Introducción al pensamiento complejo. Barcelona: Gedisa; 1990.

24. Morin E. Los 7 saberes necesarios para la Educación del Futuro. Barcelona: Ediciones Paidós Ibérica; 2011.

25. Medina MP. Pedagogías Insumisas - Movimientos político-pedagógicos y memorias colectivas de educaciones otras en A. Latina. México: Juan Pablos Editor; 2015 .

26. Freire P. Pedagogía del oprimido. Buenos Aires: Editorial S.XXI; 2015.

27. Steiner R. Fundamentos de la Antroposofía. La educación del niño desde la Antroposofía. Buenos Aires: Editorial Antroposófica; 2017.
28 . Unceta K, Acosta A, Martínez E. Desarrollo, postcrecimiento y Buen Vivir - Debates e interrogantes. Quito: EdicionesAbyaYala; 2014.

29. Acosta A. Sólo imaginando otros mundos, se cambiará éste. Reflexiones sobre el Buen Vivir. UNAD [internet]. 2010 [acceso en 2019 mar 10]; 2(1):10-17.Disponible en: https://issuu.com/ris_2009_viregional/ docs/sustentabilidades-02.

30. Alfonso R. Economia colaborativa, unnuevo mercado para laeconomía social. Rev. Econ. Púb. Soc. Cooperativa. 2016; (88):231-258.

31. Ballesteros C. Economía a escala humana. Una aproximación a los valores de la economía solidaria desde las ideas de max-neef. Rev. Nuevas Tend. Antrop. 2010; (1):89-107.

32. Max NMA. Desarrollo a escala humana. Barcelona: Icaria; 1994.

33. Felber C. La economía del bien común. Buenos Aires: Editorial Paidos; 2014.

34. Calvo P. Economía civil desde una ética de larazón cordial. Rev. Econ. Púb. Soc. Cooperativa. 2013; (79):115143.

35. Maturana H, Pörksen RB. Del Ser al Hacer. Los orígenes de la biología del conocer. Bogotá, DC: Lom Ediciones; 2004.

Recibido el 01/05/2019 Aprobado el 03/11/2019

Conflicto de intereses: inexistente

Apoyo financiero: no hubo 